\title{
Fusarium mangiferae associated with mango malformation in the Sultanate of Oman
}

\author{
M. Kvas ${ }^{1}$, E. T. Steenkamp ${ }^{1}$, A. O. Al Adawi ${ }^{2}$, M. L. Deadman ${ }^{3}$, A. A. Al Jahwari², \\ W. F. O. Marasas ${ }^{1}$, B. D. Wingfield ${ }^{4}$, R. C. Ploetz ${ }^{5}$ and M. J. Wingfield ${ }^{1}$
}

(1) Department of Microbiology and Plant Pathology, Forestry and Agricultural Biotechnology Institute (FABI), University of Pretoria, Pretoria, 0002, South Africa

(2) Ghadafan Agriculture Research Station, Ministry of Agriculture and Fisheries, P.O. Box 204, Sohar, 311, Sultanate of Oman

(3) Department of Crop Sciences, College of Agricultural and Marine Sciences, Sultan Qaboos University, P.O. Box 34, Al Khod, 123, Sultanate of Oman

(4) Department of Genetics, Forestry and Agricultural Biotechnology institute (FABI), University of Pretoria, Pretoria, 0002, South Africa

(5) Department of Plant Pathology, University of Florida, 18905 SW 280th Street, Homestead, FL 33031-3314, USA

M. Kvas

Email: marija.kvas@fabi.up.ac.za

\section{Abstract}

Mango malformation, caused by Fusarium mangiferae, represents the most important floral disease of mango. The first symptoms of this disease were noticed in the beginning of 2005 in plantations at Sohar in the Sultanate of Oman. The affected inflorescences were abnormally enlarged and branched with heavy and dried-out panicles. Based on morphology and DNA-sequence data for the genes encoding translation elongation factor $1 \alpha$ and $\beta$-tubulin, the pathogen associated with these symptoms was identified as $F$. mangiferae.

Mango (Mangifera indica) is an important perennial crop in the Sultanate of Oman and in 2004 the production of local varieties of this fruit exceeded 8,600 $\mathrm{t}$ (http://www.maf.gov.om/). In many mango-growing regions of the world, an infectious disease known as mango malformation has been reported to limit production and cause substantial economical loss (Kumar et al. 1993). The disease was first observed in India in 1891 and has since been reported from a number of countries in Asia, Africa and the Americas (Marasas et al. 2006).

Mango malformation is characterised by the abnormal development of vegetative shoots and inflorescences. The vegetative form of the disease is observed more frequently on 
young seedlings, where axillary or apical buds produce misshapen shoots, have shortened internodes and brittle leaves that are significantly smaller than those of healthy plants (Kumar et al. 1993). Malformed shoots tend to remain compact thus giving rise to a bunchy-top appearance (Kumar et al. 1993; Ploetz 1994; Marasas et al. 2006). The major symptoms of inflorescence malformation include abnormally branched and thickened panicles that produce up to three times the normal number of flowers. These flowers are unusually enlarged, sterile and do not bear fruit (Kumar et al. 1993; Ploetz 1994; Marasas et al. 2006).

Historically, the aetiology of the disease has been poorly understood. Many factors such as physiological abnormalities, viral infection, mite (Aceria mangiferae) infestation and fungal infections have been suggested as possible causal agents of the disease (Kumar et al. 1993). Various Fusarium species have been associated with the disease (Marasas et al. 2006). Although there are unpublished reports of at least three different taxa in this genus causing symptoms of malformation on mango (C. Lima, personal communication; G. Rodriguez, personal communication), a fourth taxon, F. mangiferae, is the only one which has conclusively been shown to cause mango malformation (Freeman et al. 1999; Britz et al. 2002; Marasas et al. 2006). To date, the presence of F. mangiferae has been confirmed in Egypt, Florida, Israel, Malaysia and South Africa (Britz et al. 2002; Marasas et al. 2006). Based on results with species-specific PCR primers, the pathogen may also exist in Spain (S. Freeman, personal communication). A recent report from Pakistan cannot be confirmed based on the diagnostic data it contained (Iqbal et al. 2006).

When F. mangiferae was first isolated from malformed tissue, Summanwar et al. (1966) recognized it as F. moniliforme. Later, Varma et al. (1974) used the name F. moniliforme var. subglutinans and demonstrated its involvement in both the vegetative and floral forms of the disease. Nelson et al. (1983) recognized the fungus as F. subglutinans in the section Liseola, which broadly corresponds with the so-called Gibberella fujikuroi complex (GFC) (O’Donnell et al. 1998a). To accommodate morphologically and phylogenetically-related isolates of F. subglutinans (Steenkamp et al. 2000) that had been shown previously to cause mango malformation (Freeman et al. 1999), Britz et al. (2002) established the taxon, F. mangiferae.

Early in 2005, typical symptoms of mango malformation were noticed on mango trees at Sohar, 250 km north-west of Oman's capital Muscat. These symptoms included abnormally enlarged inflorescences with thick, branched and heavy panicles (Fig. 1). To confirm the presence of mango malformation in Oman, we used DNA sequence comparisons and morphology to identify F. mangiferae in symptomatic tissue. 


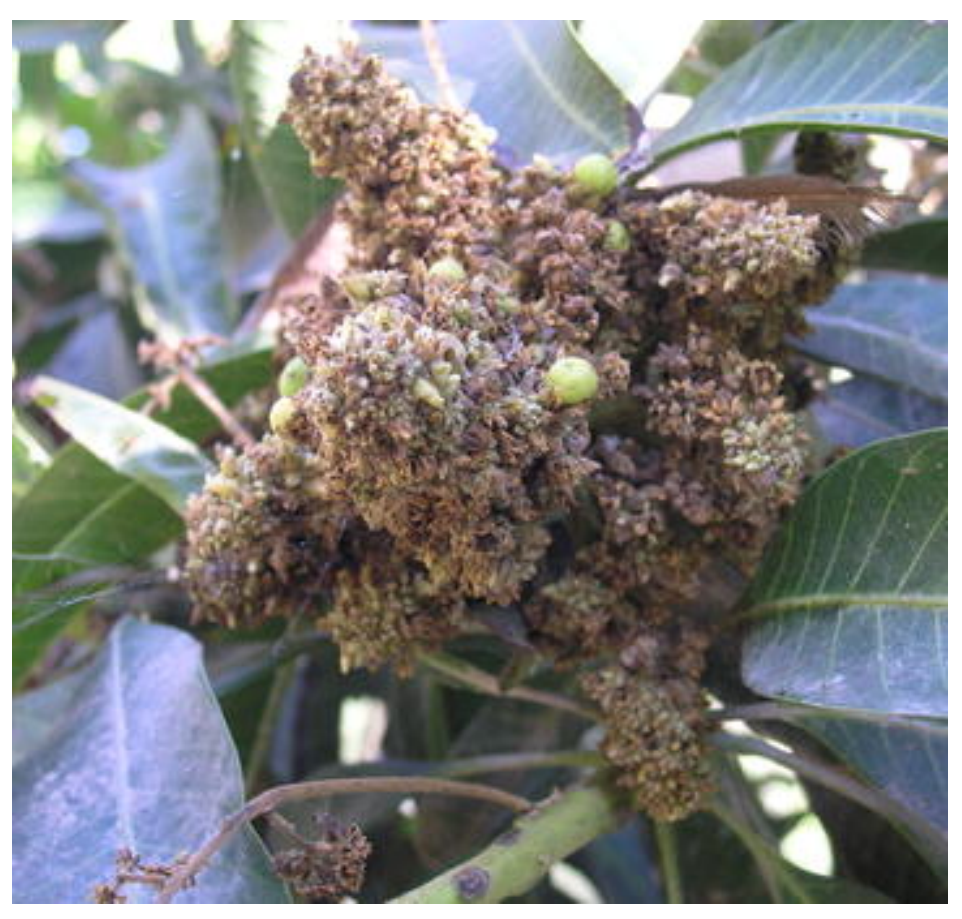

Fig. 1 Malformed inflorescence of mango collected at Sohar in the Sultanate of Oman

Samples of malformed inflorescences were collected from infected trees and surfacesterilized by submerging pieces of plant tissue in a sodium hypochlorite (1\%) solution and then in $70 \%$ ethanol for $1 \mathrm{~min}$ each. Samples were then rinsed in sterile distilled water and dried on sterile filter paper before plating small flower pieces onto $39 \mathrm{~g} \mathrm{l}^{-1}$ potato dextrose agar (PDA, Biolab, Merck). Following incubation at $25^{\circ} \mathrm{C}$ for 7 days, pure fungal cultures were obtained by single conidial spore transfers onto $20 \mathrm{~g} \mathrm{l}^{-1}$ PDA medium. All isolates are stored and maintained in the Fusarium collection of the Tree Protection Co-operative Programme, Forestry and Agricultural Biotechnology Institute (FABI), University of Pretoria, South Africa.

To determine the identity of the fungus recovered from the diseased mango tissue, three representative isolates were characterised based on morphological characteristics and DNA sequence comparisons. In order to observe morphological features, isolates were grown on $39 \mathrm{~g} \mathrm{l}^{-1}$ PDA, synthetic low nutrient agar (Nirenberg and O'Donnell 1998) and carnation leaf agar (Fisher et al. 1982). After incubation at $25^{\circ} \mathrm{C}$ for 10 days under nearultraviolet light, the isolates were examined using a light microscope and the diagnostic characters noted by Britz et al. (2002) and Nelson et al. (1983).

For the DNA comparisons, the first $\sim 700$ and $\sim 500$ bases of the genes encoding translation elongation factor $1 \alpha(\mathrm{EF} 1 \alpha)$ and $\beta$-tubulin, respectively, were sequenced. For this purpose, genomic DNA was extracted using the CTAB ( $N$-cetyl- $N, N, N$-trimethylammonium bromide) method (Steenkamp et al. 1999). The two gene regions were amplified with primer set EF1+EF2 [5'-atgggtaagga(a/g)gacaagac-3' and 5'gga(g/a)gtaccagt(g/c)atcatgtt-3'; O’Donnell et al. 1998b] and T1+T2 [5'- 
aacatgcgtgagattgtaagt-3' and 5'-tagtgacccttggcccagttg-3'; O'Donnell and Cigelnik 1997], respectively, using previously described PCR reaction and cycling conditions (Geiser et al. 2005). After purification with G50 Sephadex columns (Sigma, Steinheim, Germany), PCR products were sequenced in both directions using the original PCR primers, an ABI PRISM BigDye Terminator v3.0 Cycle Sequencing Kit (Applied Biosystems, Foster City, California) and a 3730 DNA Analyzer (Applied Biosystems). The electropherograms were visualised and corrected where necessary with Chromas Lite 2.0 (Technelysium, Australia) and BioEdit version 7.0.5.2 (Hall 1999). All EF1 $\alpha$ nucleotide sequences were compared using the BLAST search tool (Altschul et al. 1990) to those in the Fusarium identification database (Geiser et al. 2004; http://fusarium.cbio.psu.edu/) and all $\beta$-tubulin nucleotide sequences were compared to those in the database of the National Centre for Biotechnology Information (NCBI, www.ncbi.nlm.nih.gov) to obtain preliminary identifications.

Nucleotide sequences were aligned using MAFFT version 5.8 with the L-INS-i option effective (Katoh et al. 2002, 2005; http://align.bmr.kyushu-u.ac.jp/mafft/online/server/). These alignments included the sequences generated in this study, as well as those for representatives of the recognized species in the GFC (O'Donnell et al. 1998a, 2000; Geiser et al. 2005) obtained from GenBank. Relevant sequences for all of the known unique phylogenetic lineages in the so-called Asian Clade of the GFC (O'Donnell et al. 1998a, 2000) were also included. The resulting aligned datasets were analysed separately as well as combined, because they were previously shown to represent homogenous partitions (O’Donnell et al. 1998a, 2000). PAUP* 4b10 (Swofford 2003) was used to perform neighbour-joining distance (NJ) analyses and parsimony analyses using heuristic searches of 1,000 random addition replicates and tree bisection reconnection branchswapping analyses. Maximum likelihood (ML) analyses were performed with PHYML v2.1 (Guindon and Gascuel 2003) and Bayesian analyses were performed with MrBayes v3.1 (Ronquist and Heuelsenbeck 2003). The latter was based on the Metropolis-coupled Markov chain Monte Carlo search algorithm with 1,000,000 generations, and calculation of Bayesian posterior probabilities after discarding a burnin of 500 generations.

Modeltest 3.7 (Posada and Crandall 1998) and MrModelTest 2.2 (Nylander 2004; Posada and Crandall 1998) were used to determine appropriate evolutionary models for the NJ, ML and Bayesian analyses. The General Time Reversible (GTR) model (Rodríguez et al. 1990) with gamma correction for rate variation was used for EF1 $\alpha$, while the HasegawaKishino-Yano (HKY) model (Hasegawa et al. 1985) with gamma correction was used for the $\beta$-tubulin dataset. Analyses of the combined dataset utilized the GTR model with proportion invariable sites and gamma correction. ML, NJ and parsimony branch supports were estimated using 1,000 bootstrap replicates.

Morphological examination revealed that all three isolates produced macroconidia with 3-5 septa and oval microconidia in false heads from mono- and polyphialides. None of the representative isolates produced chlamydospores under the conditions tested. These morphological characters are typical of F. mangiferae, as well as most fungi previously recognized as F. subglutinans sensu lato (Britz et al. 2002). 
Results of the DNA sequence comparisons indicated that the fungi isolated from diseased Omani mango flowers, represent $F$. mangiferae. Similarity searches and sequence comparisons revealed that the EF $1 \alpha$ and $\beta$-tubulin sequences of the Oman isolates are identical to that of F. mangiferae NRRL 25226 (GenBank Accessions AF160281 and U61561; O'Donnell et al. 2000; Steenkamp et al. 2000; Britz et al. 2002). Their EF1 $\alpha$ sequences differed at two nucleotide positions from that of the ex-holotype isolate (FCC4581; Britz et al. 2002). However, results of the phylogenetic analyses clearly showed that the Oman isolates form part of the so-called Asian Clade (O'Donnell et al. 1998a, 2000) of the GFC, where they are most closely associated with known $F$. mangiferae isolates (Fig. 2). These results conclusively demonstrate that the Oman isolates from malformed mango inflorescences represent $F$. mangiferae.

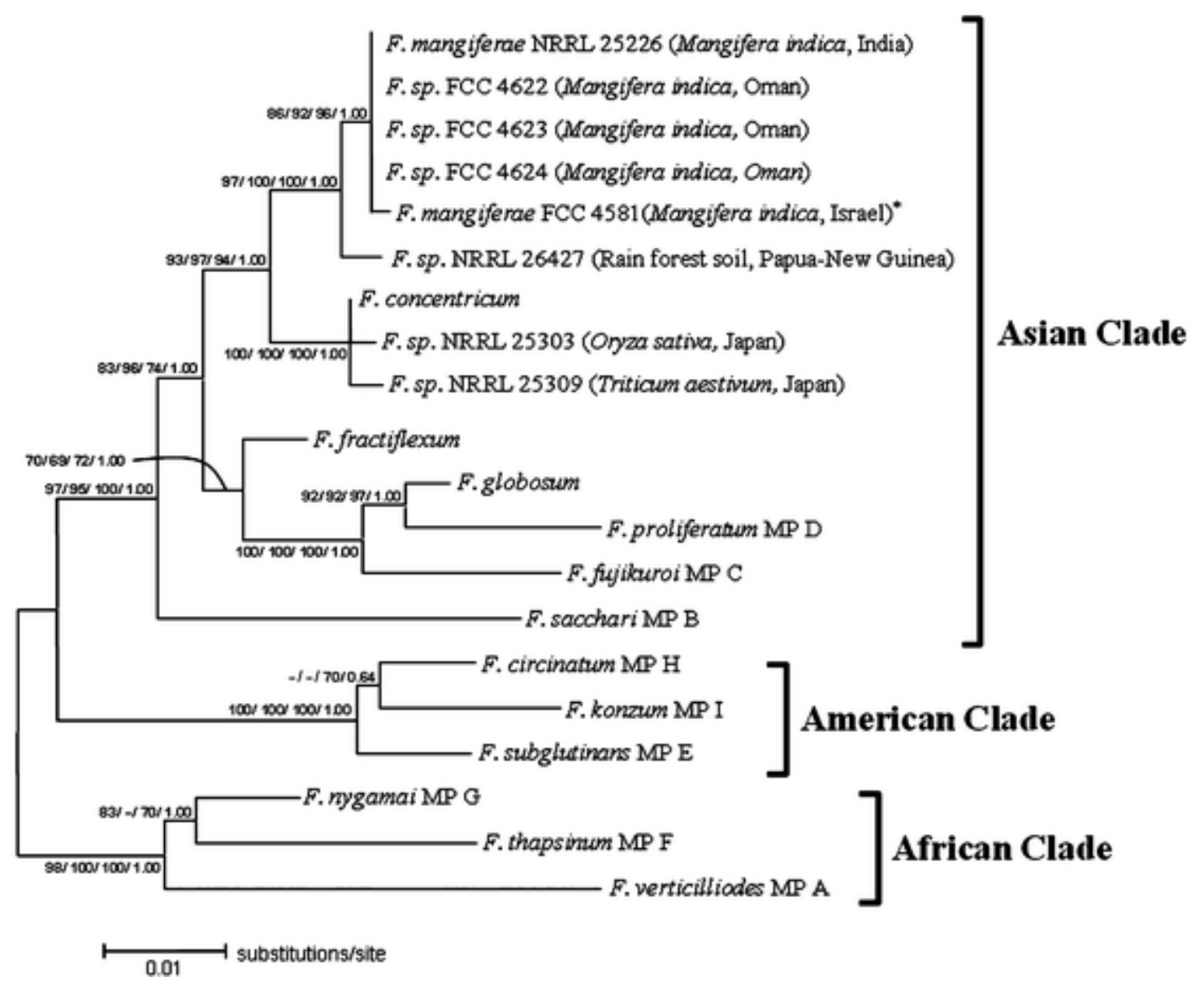

Fig. 2 A maximum likelihood phylogeny of the Gibberella fujikuroi species complex based on combined translation elongation factor $1 \alpha$ and $\beta$-tubulin sequence data. The mating populations (MP) of this complex, as well as all of the known members of the socalled Asian Clade (O'Donnell et al. 1998a, 2000) are included. The ex-holotype of F. mangiferae is indicated with an asterisk and the tree is rooted with the Fusarium species in the so-called African Clade. NJ, parsimony and Bayesian analyses of the combined dataset generated trees with topologies similar to that of the ML tree. The topologies of trees generated from analyses of the individual gene datasets were also congruent with these trees. Bootstrap support values $>60 \%$ based on 1,000 replications and Bayesian 
posterior probabilities are indicated at the branches in the order parsimony, NJ, ML and Bayesian. Branches with bootstrap support values $<60 \%$ are indicated with "-"

To the best of our knowledge, F. mangiferae and mango malformation has not previously been reported in the Sultanate of Oman. Mango malformation has the potential to have a significant negative impact on the mango industry in Oman and the Middle East as this disease significantly reduces yields. As a result, the spread of the disease must be halted by removing and burning affected trees, as well as by planting non-infected nursery supplies (Marasas et al. 2006). Research is underway to ascertain the distribution of the disease in Oman and the route by which the disease entered the country.

\section{References}

Altschul, S. F., Gish, W., Miller, W., Myers, E. W., \& Lipman, D. J. (1990). Basic local alignment search tool. Journal of Molecular Biology, 215, 403-410.

Britz, H., Steenkamp, E. T., Coutinho, T. A., Wingfield, B. D., Marasas, W. F. O., \& Wingfield, M. J. (2002). Two new species of Fusarium section Liseola associated with mango malformation. Mycologia, 94, 722-730.

Fisher, N. L., Burgess, L. W., Toussoun, T. A., \& Nelson, P. E. (1982). Carnation leaves as a substrate and for preserving cultures of Fusarium species. Phytopathology, 72, 151153.

Freeman, S., Maimon, M., \& Pinkas, Y. (1999). Use of GUS transformants of Fusarium subglutinans for determining etiology of mango malformation disease. Phytopathology, $89,456-461$.

Geiser, D. M., Jimenez-Gasco, M. M., Kang, S., Makalowski, I., Veeraraghavan, N., \& Ward, T. J., et al. (2004). FUSARIUM-ID v.1.0: A DNA sequence database for identifying Fusarium. European Journal of Plant Pathology, 110, 473-479.

Geiser, D. M., Lewis Ivey, M. L., Hakiza, G., Juba, J. H., \& Miller, S. A. (2005). Gibberella xylarioides (anamorph: Fusarium xylarioides), a causative agent of coffee wilt disease in Africa, is a previously unrecognized member of the G. fujikuroi complex. Mycologia, 97, 191-201.

Guindon, S., \& Gascuel, O. (2003). PHYML - A simple, fast, and accurate algorithm to estimate large phylogenies by maximum likelihood. Systematic Biology, 52, 696-704.

Hall, T. A. (1999). BioEdit: a user-friendly biological sequence alignment editor and analysis program for Windows 95/98/NT. Nucleic Acids Symposium Series, 41, 95-98. 
Hasegawa, M., Kishino, H., \& Yano, T. (1985). Dating of the human-ape splitting by a molecular clock of mitochondrial DNA. Journal of Molecular Evolution, 22, 160-174.

Iqbal, Z., Mehboob-ur-Rahman, Dasti, A. A., Saleem, A., \& Zafar, Y. (2006). RAPD analysis of Fusarium isolates causing "Mango Malformation" disease in Pakistan. World Journal of Microbiology and Biotechnology, 22, 1161-1167.

Katoh, K., Kuma, K., Toh, H., \& Miyata, T. (2005). MAFFT version 5: improvement in accuracy of multiple sequence alignment. Nucleic Acids Research, 33, 511-518.

Katoh, K., Misawa, K., Kuma, K., \& Miyata, T. (2002). MAFFT: a novel method for rapid multiple sequence alignment based on fast Fourier transform. Nucleic Acids Research, 30, 3059-3066.

Kumar, J., Singh, U. S., \& Beniwal, S. P. S. (1993). Mango malformation: One hundred years of research. Annual Review of Phytopathology, 31, 217-232.

Marasas, W. F. O., Ploetz, R. C., Wingfield, M. J., Wingfield, B. D., \& Steenkamp, E. T. (2006). Mango malformation disease and the associated Fusarium species.

Phytopathology, 96, 667-672.

Nelson, P. E., Toussoun, T. A., \& Marasas, W. F. O. (1983). Fusarium Species: An illustrated manual for identification. University Park, PA., USA: Pennsylvania State University Press.

Nirenberg, H. I., \& O’Donnell, K. (1998). New Fusarium species and combinations within the Gibberella fujikuroi species complex. Mycologia, 90, 434-458.

Nylander, J. A. A. (2004). MrModeltest v2. Program distributed by the author. Evolutionary Biology Centre, Uppsala University.

O’Donnell, K., \& Cigelnik, E. (1997). Two divergent intragenomic rDNA ITS2 types within a monophyletic lineage of the fungus Fusarium are nonorthologous. Molecular Phylogenetics and Evolution, 7, 103-116.

O’Donnell, K., Cigelnik, E., \& Nirenberg, H. I. (1998a). Molecular systematics and phylogeography of the Gibberella fujikuroi species complex. Mycologia, 90, 465-493.

O’Donnell, K., Kistler, H. C., Cigelnik, E., \& Ploetz, R. C. (1998b). Multiple evolutionary origins of the fungus causing Panama disease of banana: Concordant 
evidence from nuclear and mitochondrial gene genealogies. Proceedings of the National Academy of Sciences of the United States of America, 95, 2044-2049.

O’Donnell, K., Nirenberg, H. I., Aoki, T., \& Cigelnik, E. (2000). A multigene phylogeny of the Gibberella fujikuroi species complex: detection of additional phylogenetically distinct species. Mycoscience, 41, 61-78.

Ploetz, R. C. (1994). Part III. Mango. In R. C. Ploetz, G. A. Zentyer, W. T. Nishijima, K. G. Rohrbach, \& H. D. Ohr (Eds.) Compendium of Tropical Fruit Diseases (pp. 36-37).

St. Paul, MN, USA: American Pathological Society.

Posada, D., \& Crandall, K. A. (1998). Modeltest: testing the model of DNA substitution. Bioinformatics, 14, 817-818.

Rodríguez, F., Oliver, J. L., Marín, A., \& Medina, J. R. (1990). The general stochastic model of nucleotide substitution. Journal of Theoretical Biology, 142, 485-501.

Ronquist, F., \& Heuelsenbeck, J. P. (2003). MrBayes: bayesian phylogenetic inference under mixed models. Bioinformatics, 19, 1572-1574.

Steenkamp, E. T., Wingfield, B. D., Coutinho, T. A., Wingfield, M. J., \& Marasas, W. F. O. (1999). Differentiation of Fusarium subglutinans f. sp. pini by histone gene sequence data. Applied and Environmental Microbiology, 65, 3401-3406.

Steenkamp, E. T., Britz, H., Coutinho, T. A., Wingfield, B. D., Marasas, W. F. O., \& Wingfield, M. J. (2000). Molecular characterization of Fusarium subglutinans associated with mango malformation. Molecular Plant Pathology, 1, 187-93.

Summanwar, A. S., Raychaudhuri, S. P., \& Pathak, S. C. (1966). Association of the fungus Fusarium moniliforme Sheld. with the malformation in mango (Mangifera indica L.). Indian Phytopathology, 19, 227-229.

Swofford, D. L. (2003). PAUP*: Phylogenetic analysis using parsimony (* and other methods). Version 4b10. Sinauer Associates, Sunderland, Massachusetts.

Varma, A., Lele, V. C., Raychauduri, S. P., Ram, A., \& Sang, A. (1974). Mango malformation: A fungal disease. Phytopathologische Zeitschrift, 70, 254-257. 